Check for updates

Cite this: RSC Adv., 2018, 8, 22276

\title{
Selective recovery of phosphorus from acid leach liquor of iron ore by garlic peel adsorbent
}

\author{
Jiangang Sun, $\dagger^{\mathrm{a}}$ Yi-Fan Xiu, $\dagger^{\mathrm{a}}$ Kai Huang, (D) *a Jin-Tao Yu, ${ }^{\mathrm{b}}$ Shafiq Alam, ${ }^{\mathrm{c}}$ \\ Hong-Min Zhu and Zhan-Cheng Guo*b
}

Dephosphorisation of iron ore is an important challenge to the sustainable development of iron-making industry. Hydrometallurgical processing is quite effective in the reduction of phosphorus level from iron ores, where dilute sulfuric acid is commonly chosen as the lixiviant due to its prominent costeffectiveness. A cheap and effective biosorbent synthesized from garlic peel was proposed in present study to recover phosphorus selectively from acid leach liquor directly under acidic conditions near $\mathrm{pH}$ $1-2$, allowing high purity phosphorus to be recovered and the residual acid to be recycled for the next round of leaching. This proposal would sharply reduce the dephosphorisation costs of iron ore. Various batch experiments were carried out under different conditions including varying $\mathrm{pH}$, contact time, adsorbent dosages, and metal ion concentration to identify the optimal adsorption parameters for the model solutions. Results showed that the optimal $\mathrm{pH}$ for phosphate adsorption was around 1.5 and adsorption equilibrium was attained in $240 \mathrm{~min}$, and the maximum adsorption capacity for phosphate was $1.40 \mathrm{mmol} \mathrm{g}^{-1}$ and $0.81 \mathrm{mmol} \mathrm{g}^{-1}$ at equilibrium $\mathrm{pH}$ of 1.5 and 6.5 , respectively. $\mathrm{A} \mathrm{NaOH}$ solution was effective to elute the adsorbed phosphate, and the eluted solution contained mainly $\mathrm{Na}_{3} \mathrm{PO}_{4}$ and $\mathrm{NaOH}$. Recovery of phosphorus from the iron ore leach liquor by the garlic peel adsorbent was quite effective, and the adsorption efficiency could retain $85 \%$ of the original adsorption capability even after five cycles of adsorption and desorption. In summary, the Zr-loaded garlic peel appears a potential lowcost and effective adsorbent for phosphate recovery from the acid leach liquor of high phosphorus iron ore.

\author{
Received 14th April 2018 \\ Accepted 6th June 2018 \\ DOI: $10.1039 / c 8 r a 03203 c$ \\ rsc.li/rsc-advances
}

\section{Introduction}

There is huge amount of high phosphorus iron ore resources in many iron ore production areas, such as West Australia, Brazil, South Africa and Central South of China. ${ }^{1-5}$ According to the statistical survey, the reserves of high phosphorus iron ore reach 7.45 billion tons in China, and among them more than 4 billion tons was deposited in Hubei province with an average level of $1.0 \%$ phosphorus and $50 \%$ iron in mass ratios. ${ }^{6,7}$ Besides, most of it is oolitic iron ore, meaning that it is extremely difficult to carry out dephosphorization of the iron oxide minerals by traditional magnetic or floating separation methods. However the hydrometallurgical process is regarded as one of the suitable techniques for dephosphorization by acid leaching, which could reduce the phosphorous content below

${ }^{a}$ School of Metallurgical and Ecological Engineering, University of Science and Technology Beijing, Xueyuan Rd.30 Haidian District, 100083, Beijing, China. E-mail: khuang@metall.ustb.edu.cn; Tel: +86-10-62334204

${ }^{b}$ State Key Laboratory of Advanced Metallurgy, University of Science and Technology Beijing, Xueyuan Rd.30 Haidian District, 100083, Beijing, China. E-mail: zcguo@ ustb.edu.cn; Tel: +86-10-82375042

${ }^{c}$ Department of Chemical and Biological Engineering, University of Saskatchewan, 57 Campus Drive, Saskatoon, SK, Canada S7N $5 A 9$

$\dagger$ Jiangang Sun and Yi-Fan Xiu contributed equally to this study. the permissible levels in iron making industry. ${ }^{8}$ Phosphorus is one of the most harmful elements in the steel making process, and it would significantly deteriorate the quality of iron and steel products, such as increasing of hardness and brittleness and decreasing of ductility. ${ }^{9}$ Cheng's group investigated dephosphorization with acid leaching. ${ }^{1}$ In their studies, the dilute sulfuric acid of $0.1 \mathrm{~mol} \mathrm{~L}^{-1}$ was found to be effective to reduce the phosphorous content. And they pointed out that the cost of leaching process mostly depends on the consumption of leaching agents and energy of calefaction. They also gave an economic assessment of leaching cost and found it had great competition power. While in this process, how to treat the acid leach liquor is still a challenge which is usually neutralized with alkaline reagents. ${ }^{10}$ This operation is not an economic technical choice due to its consumption of huge mass of alkaline reagents and waste of the leached phosphorous as well as producing the secondary sludge. While if we can change our viewpoint apart from the traditional treatment such as chemical precipitation and make the phosphorous in the acid leach liquor be recovered in an economical way, then the operation cost of above hydrometallurgical process may decrease drastically to be very low. On the other hand, for a typical iron ore containing 1.0\% phosphorous, meaning the phosphorous in one ton of iron ore is ten kilograms, if it can be recovered in an economic and 
effective way, then it might discount the average price of each ton of iron ore by at least $25 \%$, and greatly increase the competition power of the dephosphorization of high phosphorous iron ores by acid leach. To the best of our knowledge, little work has been reported to recover phosphorus resources from the acid leach liquor of iron ores. Obviously, this is a significant challenge to the sustainable development of ironmaking industry.

Hereafter in present study, a biosorption technique was proposed, which can help to enrich the phosphorous from the real acid leach liquor of iron ore. The biosorbent was prepared by using garlic waste including peel, stem, leaves and so on as the main raw materials. Garlic is a kind of traditional flavoring vegetable and widely planted in China, and more than $80 \%$ of garlic yield of the global world is supplied by China, and therefore huge amount of garlic waste is produced in the planting areas which is usually thrown away as a useless material. ${ }^{11,12}$ In the past several years, our research group has conducted extensive studies on this abundant biowaste and successfully developed a series of interesting biosorbents used for the removal of heavy metal ion and dye contaminants, ${ }^{\mathbf{1 3 - 1 6}}$ defluoridation of drinking water, ${ }^{17}$ and selective enrichment of gold ion from the leach liquor of e-wastes. ${ }^{\mathbf{1 8 , 1 9}}$ These studies open a wide route for the recycling and reuse of common garlic waste in a high value way, bringing a new eyesight and profitmaking method for the traditional garlic farmers as well as garlic industry. Based on our preceding research work, we tried to utilize this special agro-waste in the recovery of phosphorous from the iron ore. The aim of present study was to evaluate the feasibility of using garlic waste for phosphorus recovery and the effect of common experimental parameters, such as initial $\mathrm{pH}$ value of the solution, concentration of phosphate, contact time, coexisting anions and operation cycles of adsorptiondesorption.

\section{Materials and methods}

\subsection{Materials}

All the chemicals used for synthesis and adsorption tests in this study were analytical grade. The water used in all the experiments was obtained by a double distillation system in our laboratory. The garlic waste used in this work was obtained from Shandong province in China, and was dominantly composed of peel as well as a small amount of stem and leaf.

\subsection{Preparation of the adsorbent}

The garlic waste was washed by using tap water to remove the particulate dirt like sand and clay, and then washed with distilled water. For the preparation of the adsorption particles, firstly, $100 \mathrm{~g}$ of dry garlic waste was crushed and mixed with $1000 \mathrm{~mL}$ ethanol for $24 \mathrm{~h}$ to remove pigments, volatile odor compounds and some low-molecular-weight polysaccharide. The suspension was then filtrated and the solid cake was continued to mix with $500 \mathrm{~mL}$ distilled water containing $10 \mathrm{~g}$ calcium hydroxide. In order to promote the saponification, a small amount of sodium hydroxide was added to keep the solution $\mathrm{pH}$ above 12 during the whole modification process. After agitation for around $24 \mathrm{~h}$, it was filtered and repeatedly washed with distilled water to neutral $\mathrm{pH}$. The wet filtered cake was dried in an air convection oven at $60{ }^{\circ} \mathrm{C}$ for $12 \mathrm{~h}$, and the particle size was controlled to $100-200 \mu \mathrm{m}$ by sieving. Secondly, $5 \mathrm{~g}$ of adsorbent obtained in the first pretreatment step, was

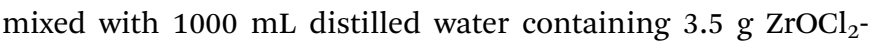
$\cdot 8 \mathrm{H}_{2} \mathrm{O}$ with the solution $\mathrm{pH}$ kept above 2 during the modification process. After agitation for around $24 \mathrm{~h}$, it was filtered and the adsorbent was repeatedly washed with distilled water to neutral $\mathrm{pH}$. The wet filtered cake was dried in an air convection oven at $60{ }^{\circ} \mathrm{C}$ for $12 \mathrm{~h}$. The final product of garlic adsorbent loaded with $\mathrm{ZrO}^{2+}$, designated as $\mathrm{Zr}$-GP particles, was used for the adsorption tests in this work.

\subsection{Batch wise adsorption tests}

Typically, in a batch wise adsorption test, $25 \mathrm{mg}$ Zr-GP dry particles and $15 \mathrm{~mL} \mathrm{PO}_{4}{ }^{3-}$ solution $\left(1 \mathrm{mmol} \mathrm{L}^{-1}\right)$, were mixed and shaken at $293 \mathrm{~K}$ for $24 \mathrm{~h}$ to attain equilibrium in a thermostatic air bath incubator reciprocating at $140 \mathrm{rpm}$. The initial $\mathrm{pH}$ value of the $\mathrm{PO}_{4}{ }^{3-}$ solution was adjusted with $0.1 \mathrm{~mol} \mathrm{~L} \mathrm{~L}^{-1} \mathrm{HNO}_{3}$ and $0.1 \mathrm{~mol} \mathrm{~L}^{-1} \mathrm{NaOH}$ solutions, and the $\mathrm{pH}$ values during the adsorption process were kept almost constant by using $0.1 \mathrm{~mol} \mathrm{~L}^{-1}$ sodium acetate as the buffer solution for each test sample. After adsorption, the $\mathrm{PO}_{4}{ }^{3-}$ solution samples were filtered and the phosphorus ion concentration in the filtrated liquor was measured by Inductive Coupled Plasma Emission Spectrometer(715-ES, Varian, American). All the required experimental solutions were diluted with $0.1 \mathrm{~mol} \mathrm{~L}^{-1} \mathrm{HNO}_{3}$ to the concentration levels suitable for analysis. All experiments were performed in duplicate at least and mean values were presented in all the cases investigated. The amount of adsorption for objective ions was calculated according to the following equations.

$$
\begin{gathered}
A=\left(C_{\mathrm{i}}-C_{\mathrm{e}}\right) / C_{\mathrm{i}} \times 100 \\
Q=\left(C_{\mathrm{i}}-C_{\mathrm{e}}\right) \times V / W
\end{gathered}
$$

where, $A$ is the adsorption percentage of objective ions on the particles (\%), $Q$ denotes the mass of objective ions adsorbed per unit mass of the adsorbent ( $\mathrm{mol} \mathrm{kg} \mathrm{kg}^{-1}$ or $\mathrm{mg} \mathrm{g}^{-1}$ ), $V$ is the solution volume $(\mathrm{mL}), W$ is the dry mass of the adsorbent $(\mathrm{kg}$ or $\mathrm{g}), C_{\mathrm{i}}$ and $C_{\mathrm{e}}$ represent the objective ion concentrations in the solution before and after adsorption $\left(\mathrm{mol} \mathrm{L}^{-1}\right)$, respectively.

\section{Results and discussion}

\subsection{Effect of pH on phosphate adsorption}

The adsorption behavior of the Zr-GP particles for phosphate ion at different equilibrium $\mathrm{pH}$ values is shown in Fig. 1. It shows the percentage adsorption of phosphorus ion as a function of equilibrium $\mathrm{pH}$ at an initial $\mathrm{PO}_{4}{ }^{3-}$ concentration of $1 \mathrm{mmol} \mathrm{L}^{-1}$. As seen in the figure, the optimum $\mathrm{pH}$ for phosphate adsorption was $1-1.5$, and the adsorption percentage was more than $90 \%$ under the investigated conditions. When the equilibrium $\mathrm{pH}$ was 7-14, the adsorption percentage decreases rapidly with increasing $\mathrm{pH}$, which may be due to the 


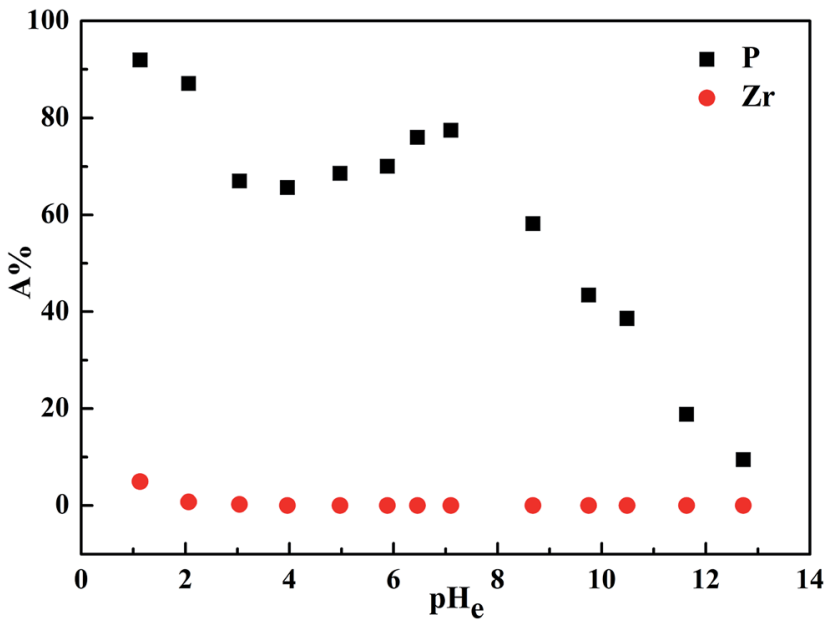

Fig. 1 Effect of $\mathrm{pH}$ on the adsorption of phosphate and the dissolution percentage of zirconium on the $\mathrm{Zr}$-GP particles. Dry weight of the particles $=25 \mathrm{mg}$, volume of solution $=15 \mathrm{~mL}$, initial concentration of $\mathrm{PO}_{4}{ }^{3-}=1 \mathrm{mmol} \mathrm{L}{ }^{-1}$, contact time $=24 \mathrm{~h}$, temp. $=293 \mathrm{~K}$.

competitive adsorption of $\mathrm{OH}^{-}$onto the particle surface and hence the electrostatic repulsion for $\mathrm{PO}_{4}{ }^{3-}$ anions. Above adsorption results suggest that Zr-GP particles show quite unique adsorption behavior that it can directly adsorb the phosphate anion from the acidic aqueous solution, which helps to reduce the consumption of the alkaline reagent to adjust the solution pH levels. Simultaneously, the loss of loaded zirconium during the adsorption process was also monitored, and it can be seen that at $\mathrm{pH}$ near 1.0 , about $4 \%$ of loaded zirconium was lost due to the dissolution, while at higher $\mathrm{pH}$, there was no loss of zirconium. The loading of zirconium can be regarded as a cation exchange process, so at low $\mathrm{pH}, \mathrm{H}^{+}$may substitute for some $\mathrm{ZrO}^{2+}$ due to the competitive reaction with the functional groups of the garlic peel particles. Based on above results, $\mathrm{pH}$ 1.5 is recommended as the optimal $\mathrm{pH}$ for phosphorous adsorption without loaded zirconium loss.

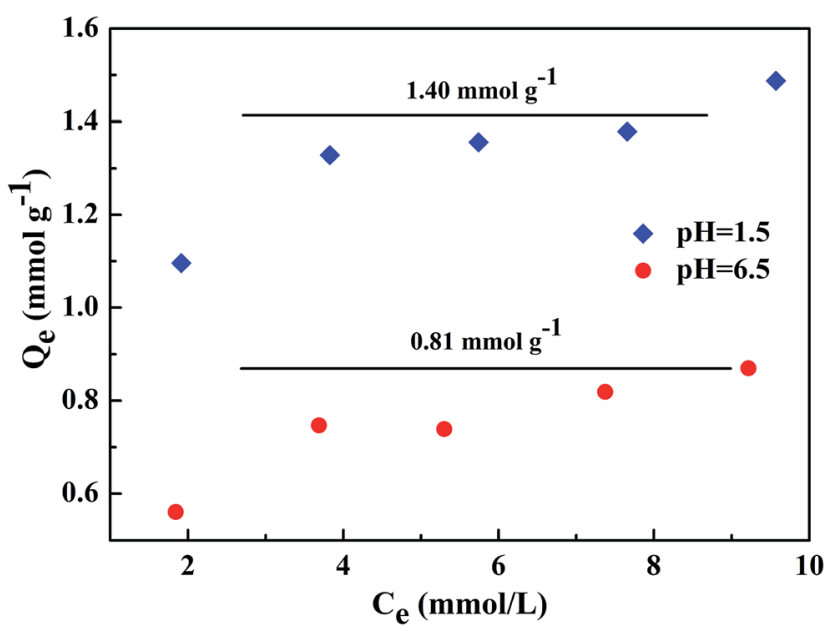

Fig. 2 Adsorption isotherm of phosphate ions onto the $\mathrm{Zr}$-GP particles. Dry weight of the particles $=25 \mathrm{mg}$, volume of solution $=15 \mathrm{~mL}$, $\mathrm{pH}=1.5$ and 6.5 , contact time $=24 \mathrm{~h}$, temp. $=293 \mathrm{~K}$.

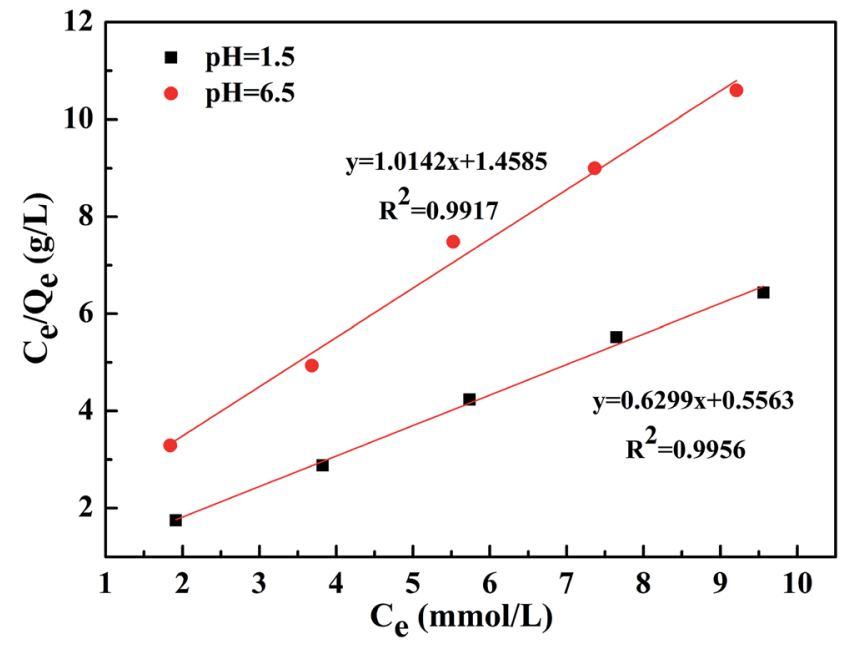

Fig. 3 Fitting curves based on the Langmuir model. Dry weight of the particles $=25 \mathrm{mg}$, volume of solution $=15 \mathrm{~mL}, \mathrm{pH}=1.5$ and 6.5 , contact time $=24 \mathrm{~h}$, temp. $=293 \mathrm{~K}$.

\subsection{Adsorption isotherms}

The adsorption isotherms of the phosphate ion on the Zr-GP particles are shown in Fig. 2, from which it can be evaluated that the maximum loading capacity for this particle is $1.40 \mathrm{mmol} \mathrm{g}^{-1}$ and $0.81 \mathrm{mmol} \mathrm{g}^{-1}$ at an equilibrium $\mathrm{pH}$ of 1.5 and 6.5 , respectively. The larger adsorption of phosphate at $\mathrm{pH}$ 1.5 suggested that $\mathrm{H}^{+}$had a significant positive effect on the adsorption. Biswas has ever reported an adsorption capacity for phosphate by Zr-loaded orange juice particles of $57 \mathrm{mg}-\mathrm{P} \mathrm{g}^{-1}$ at $\mathrm{pH} 3.0 .^{20}$ Here, the adsorption capacity was $43.4 \mathrm{mg}-\mathrm{P} \mathrm{g}^{-1}$ at pH 1.5 , indicating comparable values for the phosphate adsorption. Further study showed that the adsorption process fits the Langmuir model, as shown in Fig. 3, which suggested that the adsorption of phosphate on the Zr-GP particles followed a kind of monolayer adsorption model.

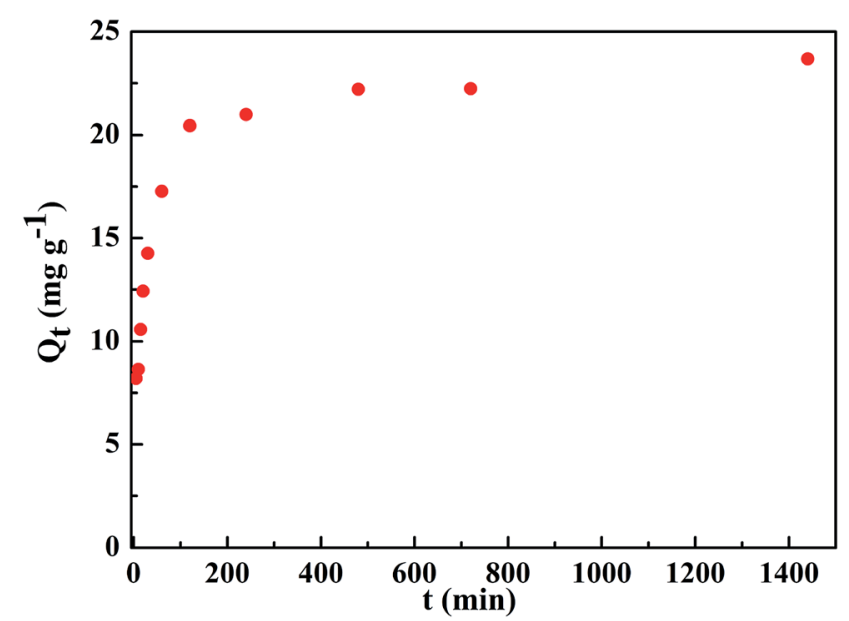

Fig. 4 Variation of adsorption capacity of phosphate onto the $\mathrm{Zr}$-GP particles at different contact time. Dry weight of the particles $=25 \mathrm{mg}$, volume of solution $=15 \mathrm{~mL}$, initial concentration of $\mathrm{PO}_{4}{ }^{3-}=1 \mathrm{mmol}$ $\mathrm{L}^{-1}, \mathrm{pH}=1.5$, temp. $=293 \mathrm{~K}$. 


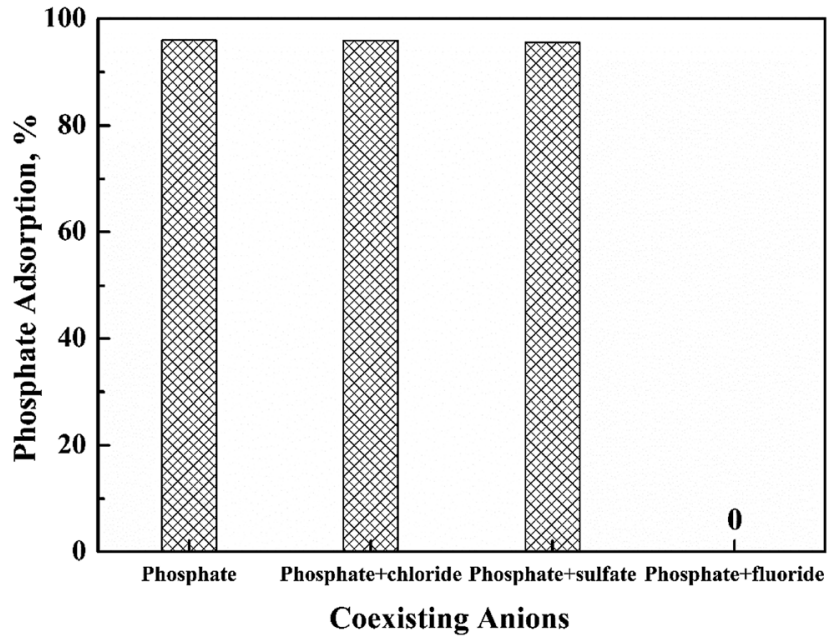

Fig. 5 Variation of adsorption capacity of phosphate onto the Zr-GP particles at different coexisting anions. Dry weight of the particles $=$ $25 \mathrm{mg}$, volume of solution $=15 \mathrm{~mL}$, initial concentration of $\mathrm{PO}_{4}{ }^{3-}=$ $1 \mathrm{mmol} \mathrm{L}^{-1}$ and coexisting anions $=0.1 \mathrm{~mol} \mathrm{~L}^{-1}, \mathrm{pH}=1.5$, contact time $=24 \mathrm{~h}$, temp. $=293 \mathrm{~K}$.

\subsection{Effect of adsorption time}

Fig. 4 shows the effect of contact time on the adsorption of phosphate on the Zr-GP particles. It can be seen that the adsorption increased with increasing contact time from 5 to $240 \mathrm{~min}$ and then approached a platform level in the range of 240-1440 min.

\subsection{Effect of coexisting anions}

Coexisting anions such as chloride, sulfate and fluoride may compete with phosphate during the adsorption process for the active sites on the Zr-GP particles. Hence, the effect of these competitive anions on the adsorption of phosphate was evaluated. Anion solutions of chloride, sulfate and fluoride were prepared by dissolving appropriate amount of their sodium salts in the distilled water, respectively. Adsorption experiments were carried out by adding a certain volume of these anion solutions, respectively, in the phosphate solution to make the test solutions containing $1 \mathrm{mmol} \mathrm{L}^{-1} \mathrm{PO}_{4}{ }^{3-}$ and $0.1 \mathrm{~mol} \mathrm{~L}^{-1}$ individual coexisting anion. The effect of various coexisting anions on phosphate adsorption by particles is shown in Fig. 5, which indicates that chloride and sulfate had no significant
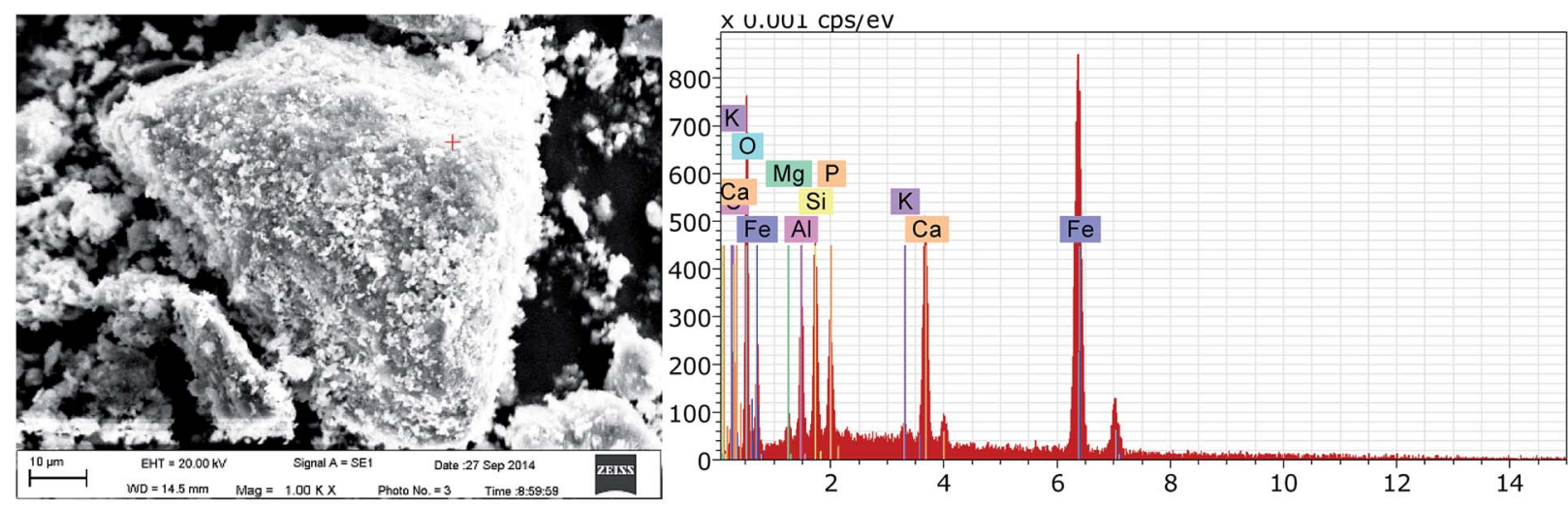

(a) Raw iron ore before acid leaching
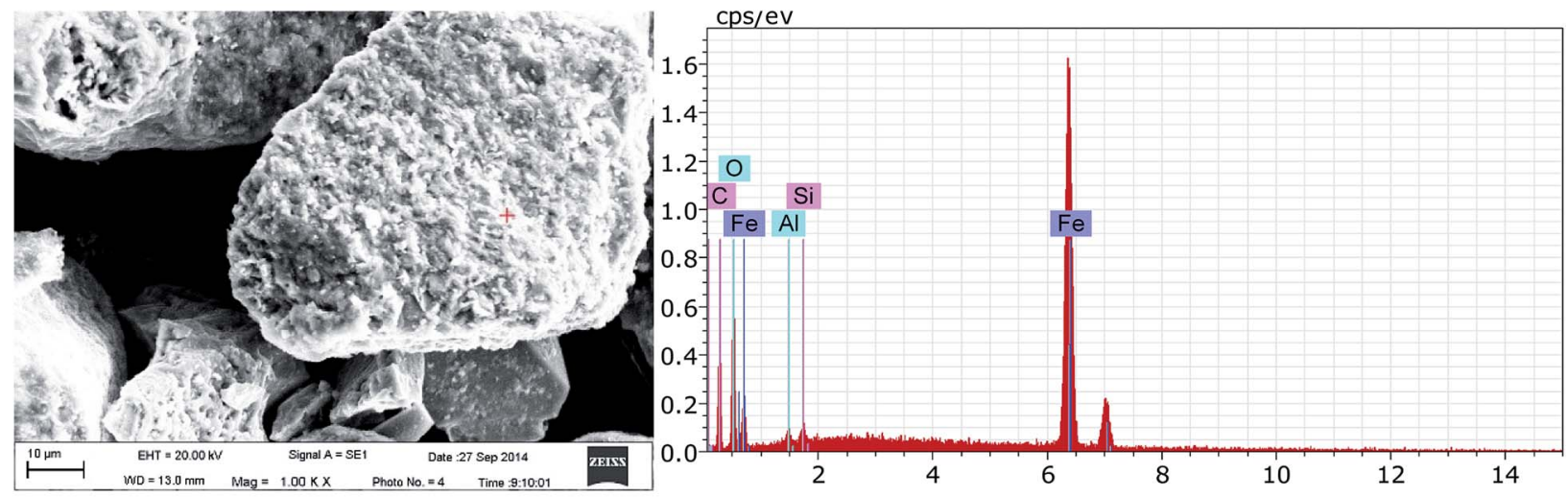

(b) Iron ore after acid leaching

Fig. 6 Scanning electron micrograph and spectra of high phosphorus iron ore. 


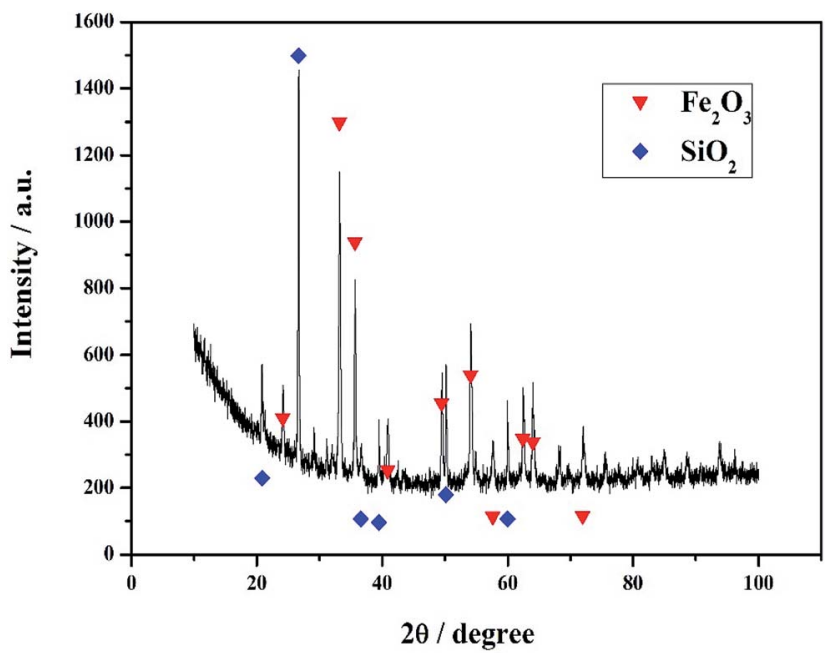

Fig. 7 X-ray diffraction pattern of high phosphorus iron ore after acid leaching.

inverse effect on the adsorption of phosphate, while fluoride significantly suppressed the adsorption of phosphate onto the particles. As mentioned in Fig. 1, the high $\mathrm{pH}$ drastically inhibited the adsorption of phosphate onto the Zr-GP particles. Despite the similar negative charge of $\mathrm{Cl}^{-}, \mathrm{F}^{-}$and $\mathrm{SO}_{4}{ }^{2-}$ as $\mathrm{OH}^{-}$, but only $\mathrm{OH}^{-}$and $\mathrm{F}^{-}$competed for adsorption with $\mathrm{PO}_{4}{ }^{3-}$, while $\mathrm{Cl}^{-}$and $\mathrm{SO}_{4}{ }^{2-}$ had no effect, as demonstrated in Fig. 5. Therefore, it can be deduced that the electrostatic repulsion was not only the indispensable factor influencing the adsorption of phosphate, but also its complexation affinity with the $\mathrm{ZrO}^{2+}$ as the kernel metal is the key to determine the effectiveness of competitive power. The anions of $\mathrm{Cl}^{-}$and $\mathrm{SO}_{4}{ }^{2-}$ do not easily form complex molecules with $\mathrm{ZrO}^{2+}$, while $\mathrm{OH}^{-}$ and $\mathrm{F}^{-}$are much easy to form complexes than that of $\mathrm{PO}_{4}{ }^{3-}$, which made the difference. Above results suggest that in the leaching media of the dilute sulfuric acid or hydrochloric acid, the adsorption of phosphate onto the Zr-loaded adsorbents can be kept effective without worrying about the inhibition effect from the anions of $\mathrm{SO}_{4}{ }^{2-}$ and $\mathrm{Cl}^{-}$.

\subsection{Leaching test of real iron ore}

High phosphorus iron ore, used in this study, was obtained from Hubei province in China. Firstly, the ore was crushed and screened to obtain $0.074-0.1 \mathrm{~mm}$ size fraction. Such $100 \mathrm{~g}$ ore powder was mixed with $1000 \mathrm{~mL}$ dilute sulfuric acid under an intensive agitation at $\mathrm{pH} 0.8-1$ for $2 \mathrm{~h}$, then filtered. Fig. 6 shows

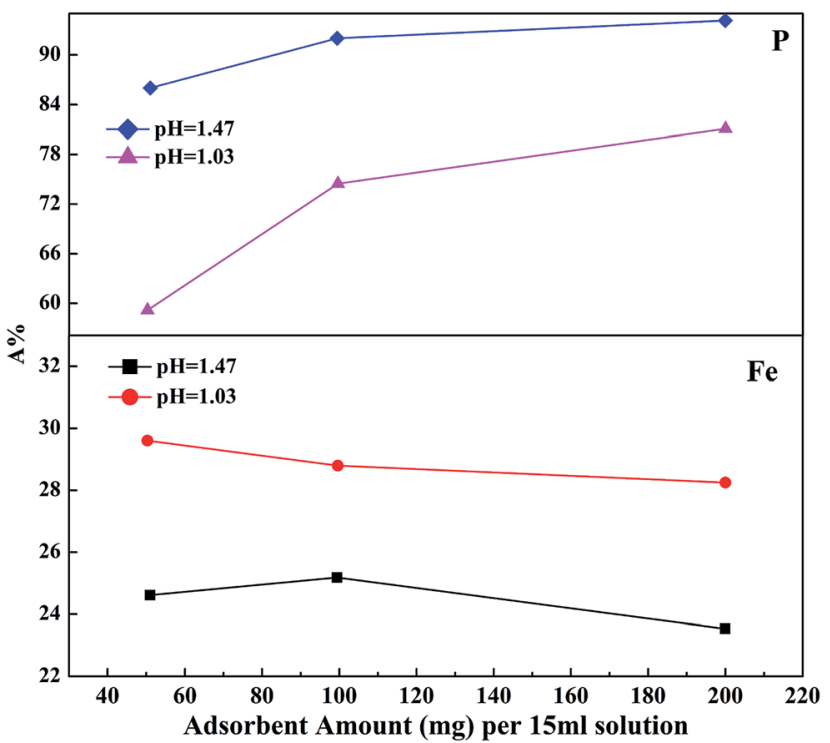

Fig. 8 Effect of particle dosage on the adsorption capacity of phosphate onto the $\mathrm{Zr}$-loaded particles. Volume of solution $=15 \mathrm{~mL}$, initial concentration of $\mathrm{PO}_{4}{ }^{3-}=78.25 \mathrm{mg} \mathrm{L}^{-1}$ and iron ion $=154.68 \mathrm{mg} \mathrm{L}^{-1}$, $\mathrm{pH}=1.03$ and 1.47, contact time $=6 \mathrm{~h}$, temp. $=293 \mathrm{~K}$.

the SEM photo and EDX spectra of the surface of high phosphorus iron ore before (a) and after (b) acid leaching. It was shown that from the spectra, there were quite a few elements demonstrated in the high phosphorus iron ore before acid leaching, such as $\mathrm{Fe}, \mathrm{Al}, \mathrm{Si}, \mathrm{Ca}, \mathrm{Mg}, \mathrm{K}$ and $\mathrm{P}$, while after acid leaching, the iron ores showed more simple chemical components, and most of $\mathrm{Ca}, \mathrm{Mg}, \mathrm{K}$ and $\mathrm{P}$ were removed by acid leaching, as shown in the figures, there are only $\mathrm{Fe}, \mathrm{Al}$ and $\mathrm{Si}$ left in the iron ores. The XRD result further verified that the iron ore after acid leaching mainly consisted of $\mathrm{Fe}_{2} \mathrm{O}_{3}$ and $\mathrm{SiO}_{2}$, as shown in Fig. 7, which suggested that the acid leaching was quite effective to extract phosphorous and other elements from the iron ore. It also can be deduced that in the acid leach liquor, the soluble species were numerous and complex, and selective recovery of phosphorous from such aqueous solution, is not easy due to the interfering effect from other coexisting ions. To make clear the chemical components in the leach liquor in details, $200 \mathrm{~mL}$ acid leach liquor was dried in an air convection oven at $100{ }^{\circ} \mathrm{C}$ for $24 \mathrm{~h}$, and the obtained solid crystals were used for XRF analysis. Table 1 shows the XRF results of the raw high phosphorus iron ore, solid obtained from the acid leach liquor by drying and crystallization, and iron ore residuals after acid leaching. It can be seen that the content of phosphorus in the iron ore decreased from $3.17 \%$ to $0.51 \%$ before and after

Table 1 XRF results of the iron ore before (no. 1) and after (no. 3) acid leaching, the crystalline solid (no. 2) after evaporation of the acid leach liquor

\begin{tabular}{|c|c|c|c|c|c|c|c|c|c|}
\hline No. & Elements & $\mathrm{Fe}_{2} \mathrm{O}_{3}$ & $\mathrm{SiO}_{2}$ & $\mathrm{CaO}$ & $\mathrm{Al}_{2} \mathrm{O}_{3}$ & $\mathrm{P}_{2} \mathrm{O}_{5}$ & $\mathrm{SO}_{3}$ & $\mathrm{MgO}$ & $\mathrm{MnO}$ \\
\hline 1 & Percentage, \% & 66.06 & 14.11 & 6.99 & 5.89 & 3.17 & 1.56 & 1.16 & 0.33 \\
\hline 2 & & 27.17 & 6.68 & 13 & 5.2 & 8.99 & 33.25 & 2.26 & 1.91 \\
\hline
\end{tabular}




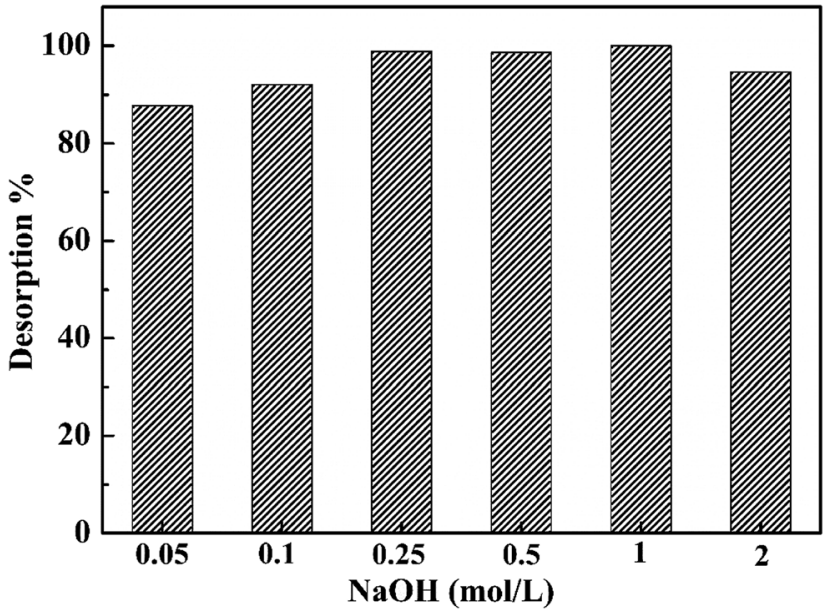

Fig. 9 Effect of $\mathrm{NaOH}$ solution on the elution percentage of the adsorbed phosphate on the particles. Dry weight of the particles $=$ $50 \mathrm{mg}$, volume of solution $=25 \mathrm{~mL}$, initial concentration of $\mathrm{PO}_{4}{ }^{3-}=$ $1 \mathrm{mmol} \mathrm{L}^{-1}$, adsorption $\mathrm{pH}=1.5$, adsorption and desorption contact time $=24 \mathrm{~h}$, temp. $=293 \mathrm{~K}$.

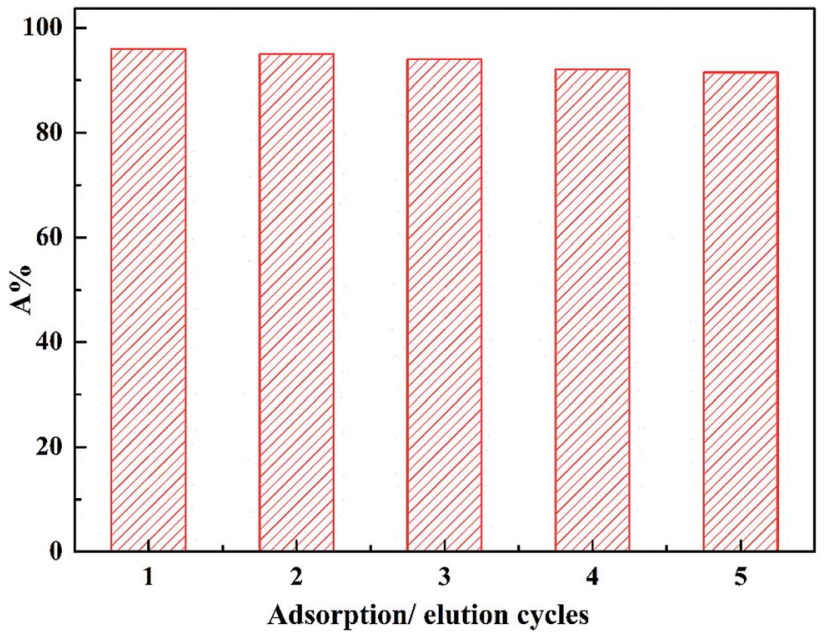

Fig. 11 Variation of adsorption percentage of phosphate onto the $\mathrm{Zr}$ GP particles at different adsorption and elution cycles. Dry weight of the particles $=256 \mathrm{mg}$, volume of solution $=40 \mathrm{~mL}$, initial concentration of $\mathrm{PO}_{4}{ }^{3-}=4.5 \mathrm{mmol} \mathrm{L}^{-1}, \mathrm{pH}=1.65$, adsorption and desorption contact time $=24 \mathrm{~h}$, temp. $=293 \mathrm{~K}$.
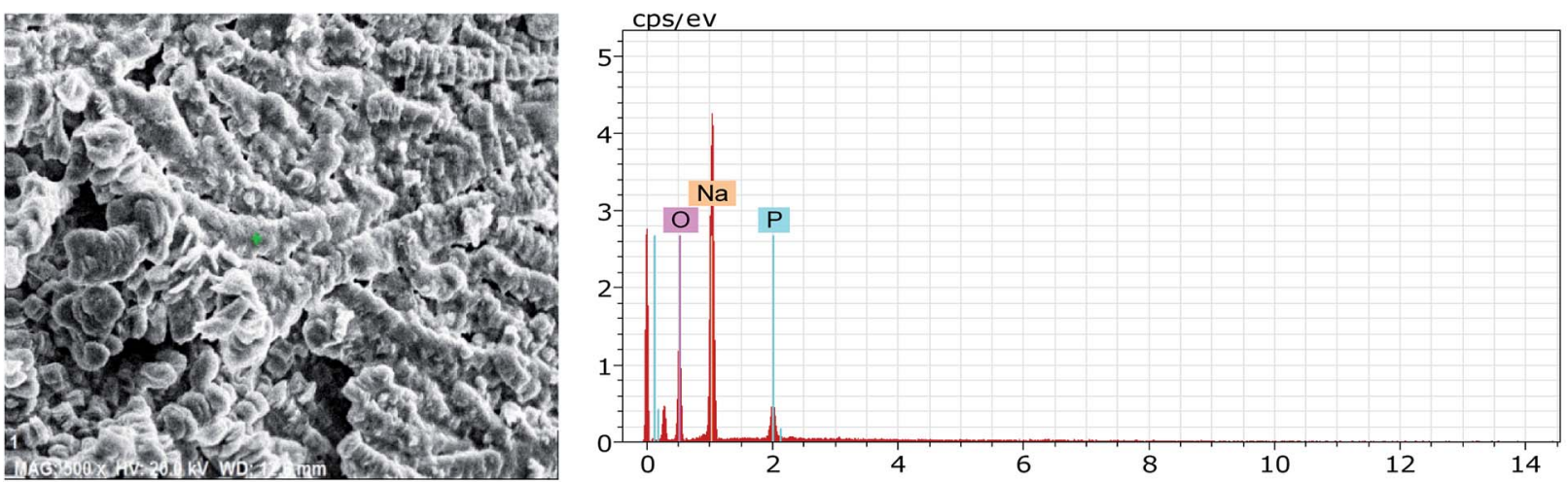

(a) Crystalline solid of eluted solution $\left(\mathrm{Na}_{3} \mathrm{PO}_{4}\right)$
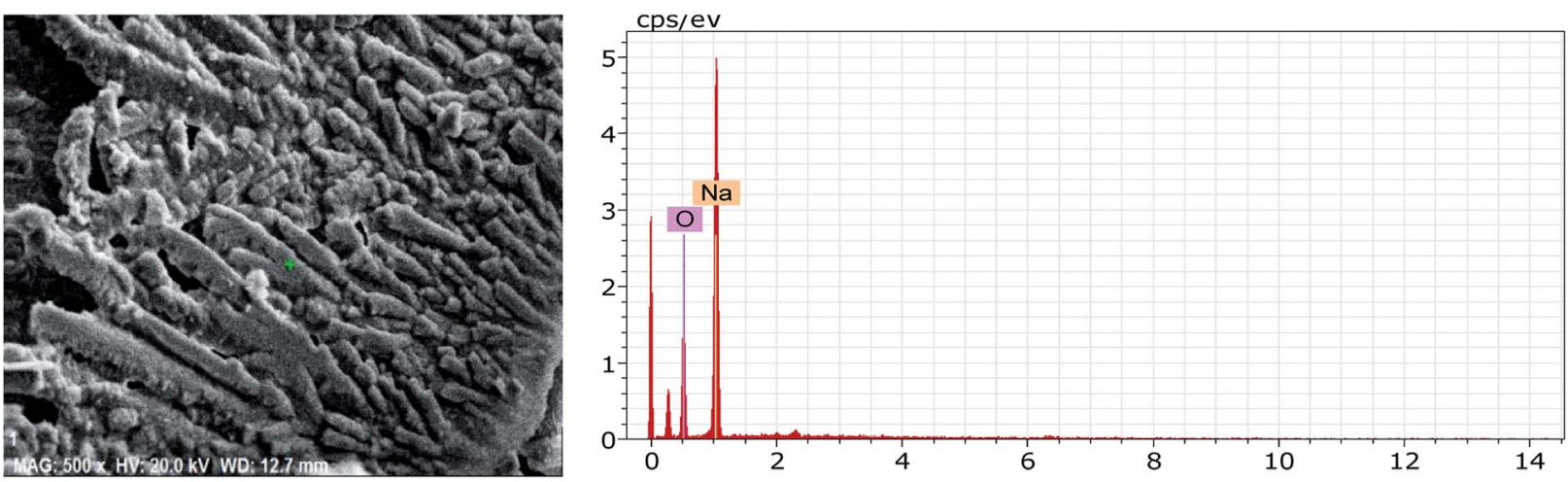

(b) Crystalline solid of eluted solution $(\mathrm{NaOH})$

Fig. 10 Scanning electron micrograph and EDX spectra of crystalline solid of eluted solution. 

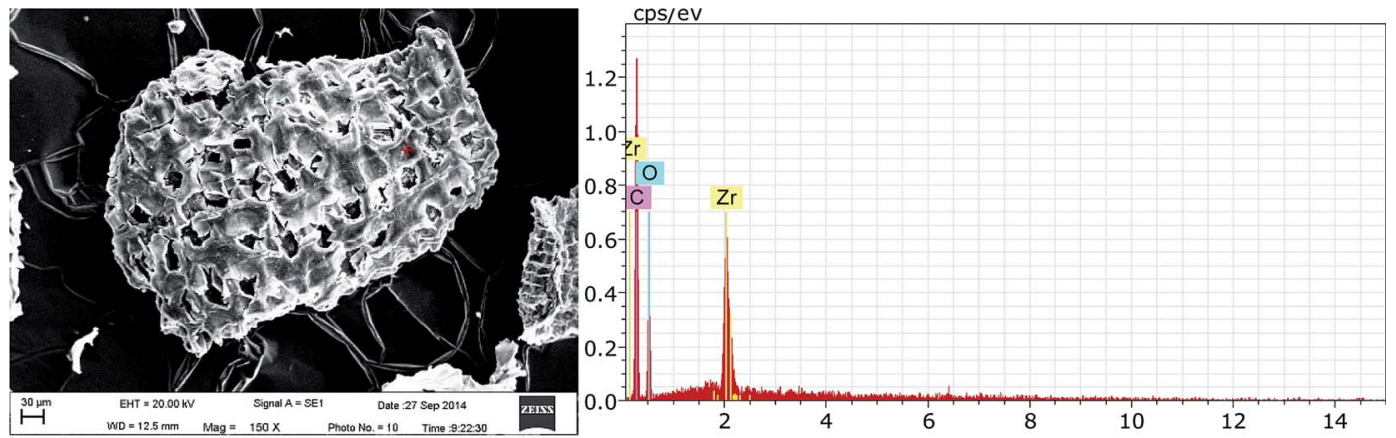

(a) Adsorbent before adsorption
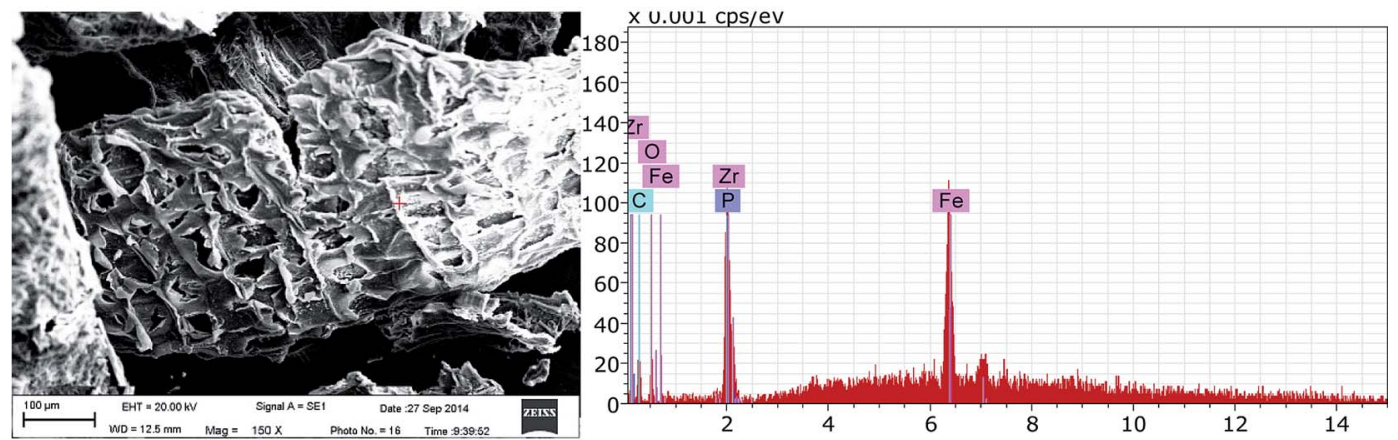

(b) Adsorbent after adsorption
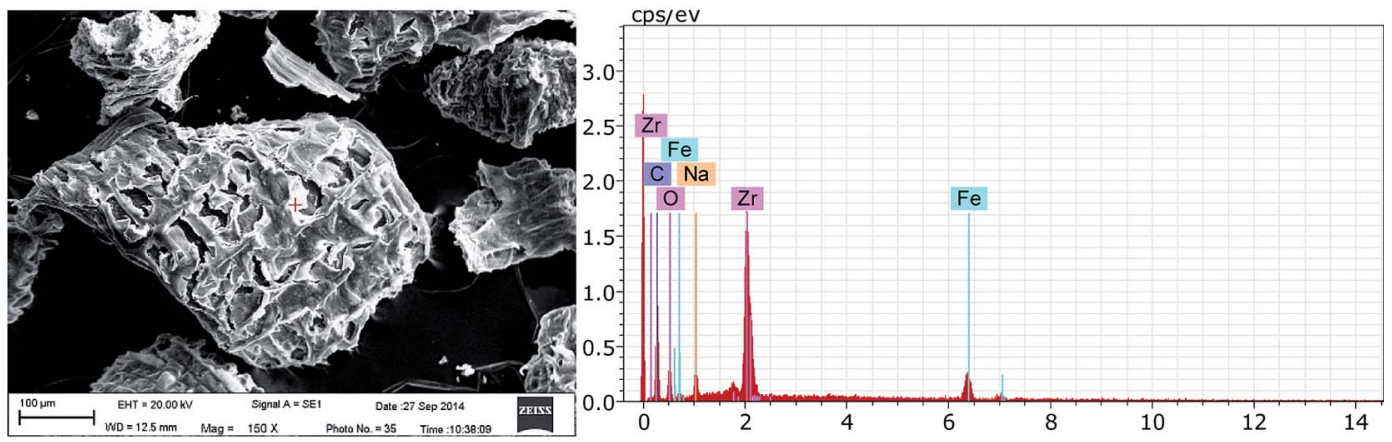

(c) Adsorbent after desorption

Fig. 12 Scanning electron micrograph and EDX spectra of the surface of Zr-GP particles.

acid leaching, respectively, meaning that it was effectively extracted into the acid leach liquor.

\subsection{Effect of particles dosage}

Fig. 8 shows the effect of Zr-GP particle dosage on the phosphate adsorption and iron ion from acid leach liquor of the high phosphorus iron ore. The initial concentrations of phosphate and iron ion are $78.25 \mathrm{mg} \mathrm{L}^{-1}$ and $154.68 \mathrm{mg} \mathrm{L}^{-1}$ for both leach liquor at pH 1.03 and 1.47, respectively. It can be seen that the phosphate adsorption was effective at above two $\mathrm{pHs}$, and $\mathrm{pH}$ 1.47 is obviously beneficial to the adsorption of $\mathrm{PO}_{4}{ }^{3-}$, probably due to less loss of loaded zirconium at this $\mathrm{pH}$ than that of $\mathrm{pH}$ 


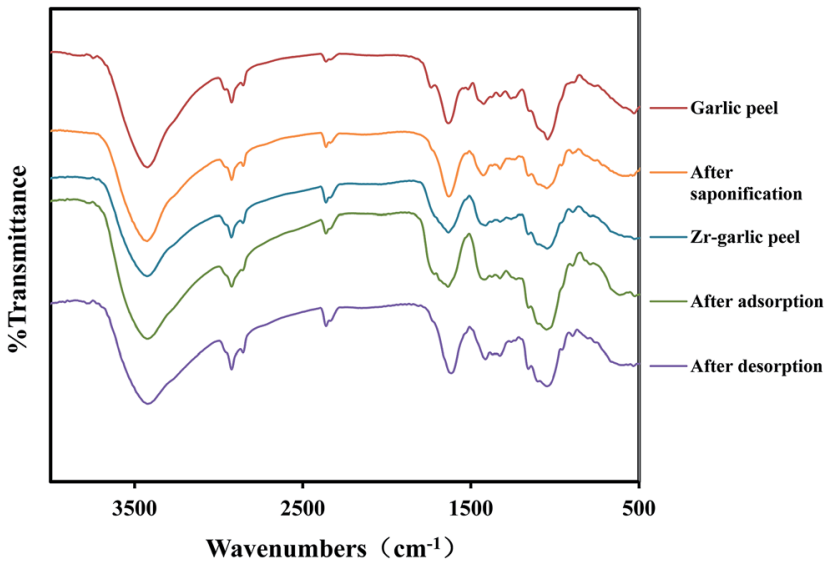

Fig. 13 FT-IR spectra for a series of garlic peel particles treated at different processes.

1.03. At the same time, a small amount (around 20-30\%) of iron ions $\left(\mathrm{Fe}^{3+}\right)$ was also adsorbed by the adsorbent, which may occupy some active functional groups of garlic peel in the surface of the particles and weakened the adsorption of phosphate.

\subsection{Repeating adsorption and desorption test}

Regeneration and reuse of the Zr-GP particles without adsorption loss is crucial to the practical application. The experimental results demonstrated that sodium hydroxide solution as the elution solvent was quite effective, as indicated in Fig. 1, higher $\mathrm{pH}$ inhibited the adsorption of phosphate on the particles. It was also attempted to elute the adsorbed phosphate off the particles by using dilute acid, such as $0.5 \mathrm{~mol} \mathrm{~L}^{-1} \mathrm{HCl}, \mathrm{HNO}_{3}$ and $\mathrm{H}_{2} \mathrm{SO}_{4}$, and it was found that no more than $30 \%$ of phosphate can be desorbed. Fig. 9 shows the effect of desorption at different concentration of sodium hydroxide solution, and it can be seen that $1 \mathrm{~mol} \mathrm{~L}^{-1} \mathrm{NaOH}$ was quite effective. In order to know the chemical compositions of the eluted solution, $50 \mathrm{~mL}$ of eluted solution was dried and evaporated to obtain the crystalline solid, which was sent for SEM and EDX analyses. As shown in Fig. 10, it was found that the solids are agglomerated or dendrite corresponding to the main components of $\mathrm{Na}_{3} \mathrm{PO}_{4}$ and $\mathrm{NaOH}$, respectively.

Fig. 11 shows the variation of the generated Zr-GP particles adsorption capacity via five cycles of adsorption-desorption tests. It indicated that even after five cycles of adsorption and elution, the adsorption efficiency of Zr-GP particles for phosphate was still kept at about $85 \%$ of the original capability. A little decrease of the adsorption may be due to the following reasons, such as loss of loaded zirconium, accumulating cover of the particles surface by some solid impurities, or some denaturation of the biomass particles during the repeating adsorption and desorption process.

\subsection{Characterization of the particles before and after adsorption}

Fig. 12 shows the SEM photo and EDX spectra of the surface of Zr-GP particles before adsorption (a), after adsorption (b) and after desorption (c) of phosphate. It is clear that the surface morphology of the particles is rough and porous which is favorable for objective ions to penetrate into the particles and be trapped or adsorbed by the particles, and after desorption, the particles still maintained its morphology and shape well which indicated the good toughness of the Zr-GP particles. From the spectra in Fig. 12(b), it was found that the phosphorus has been adsorbed by Zr-GP particles, while quite a bit of iron was also captured on the particles. After elution by $1 \mathrm{~mol} \mathrm{~L}^{-1}$ $\mathrm{NaOH}$ solution, the EDX peak of phosphorus on the particles disappeared completely, but a small amount of iron was still left on the particles, which suggested that $\mathrm{NaOH}$ solution could not effectively elute the loaded iron ions, and more appropriate elution modes and parameters need to be explored. In order to illustrate more detailed information about these processes, FTIR spectrum was conducted for the related garlic peel particles and the results are shown in Fig. 13.

\subsection{Mechanism of modification, adsorption and desorption}

The adsorption peaks at $3424.37 \mathrm{~cm}^{-1}$ were attributed to the O-H stretching vibrations of cellulose, absorbent water, or hemicelluloses. The peaks at $2923.01 \mathrm{~cm}^{-1}$ were attributed to the $-\mathrm{CH}_{2}$ - asymmetric vibrations. The peaks at $1634.92 \mathrm{~cm}^{-1}$ correspond to the asymmetric stretching vibration of $\mathrm{C}=\mathrm{O}$ bond in ionic carboxylic groups of -COO-, which may be assigned to the functional groups from the pectic acid, polyphenolic and alliin acid, which are discussed in detail later. The peaks at $1423.5 \mathrm{~cm}^{-1}$ were attributed to the aromatic skeleton and the $\mathrm{C}-\mathrm{H}$ in-plane bending vibration (Table 2).

Table 2 FT-IR wavenumbers and corresponding functional groups ${ }^{a}$

\begin{tabular}{|c|c|c|c|c|c|c|c|c|}
\hline \multirow[b]{2}{*}{ Particle samples } & \multicolumn{8}{|c|}{ Wavenumbers at different peaks $\left(\mathrm{cm}^{-1}\right)$} \\
\hline & $\mathrm{O}-\mathrm{H}$ & $-\mathrm{CH}_{2}^{-}$ & $\mathrm{C}=\mathrm{O}$ & Arene, $\mathrm{C}-\mathrm{H}$ & $\mathrm{C}-\mathrm{C}, \mathrm{C}-\mathrm{O}, \mathrm{O}-\mathrm{H}$ & $\mathrm{C}-\mathrm{O}$ & & \\
\hline Crude garlic peel & 3424.37 & 2923.01 & 1634.92 & 1423.5 & 1260.71 & 1043.93 & 529.93 & ND \\
\hline Saponified peel & 3426.15 & 2922.78 & 1631.74 & 1427.29 & 1326.78 & 1048.1 & 584.19 & ND \\
\hline Zr-garlic peel & 3425.99 & 2924.19 & 1634.17 & 1413.05 & ND & 1046.72 & ND & 448.37 \\
\hline After adsorption & 3424.76 & 2922.96 & 1636.37 & 1421.31 & ND & 1049.7 & 525.28 & ND \\
\hline After desorption & 3423.37 & 2923.25 & 1616.92 & 1413.53 & ND & 1048.05 & 532.93 & 403.68 \\
\hline
\end{tabular}

${ }^{a} \mathrm{ND}$ - no detection. 

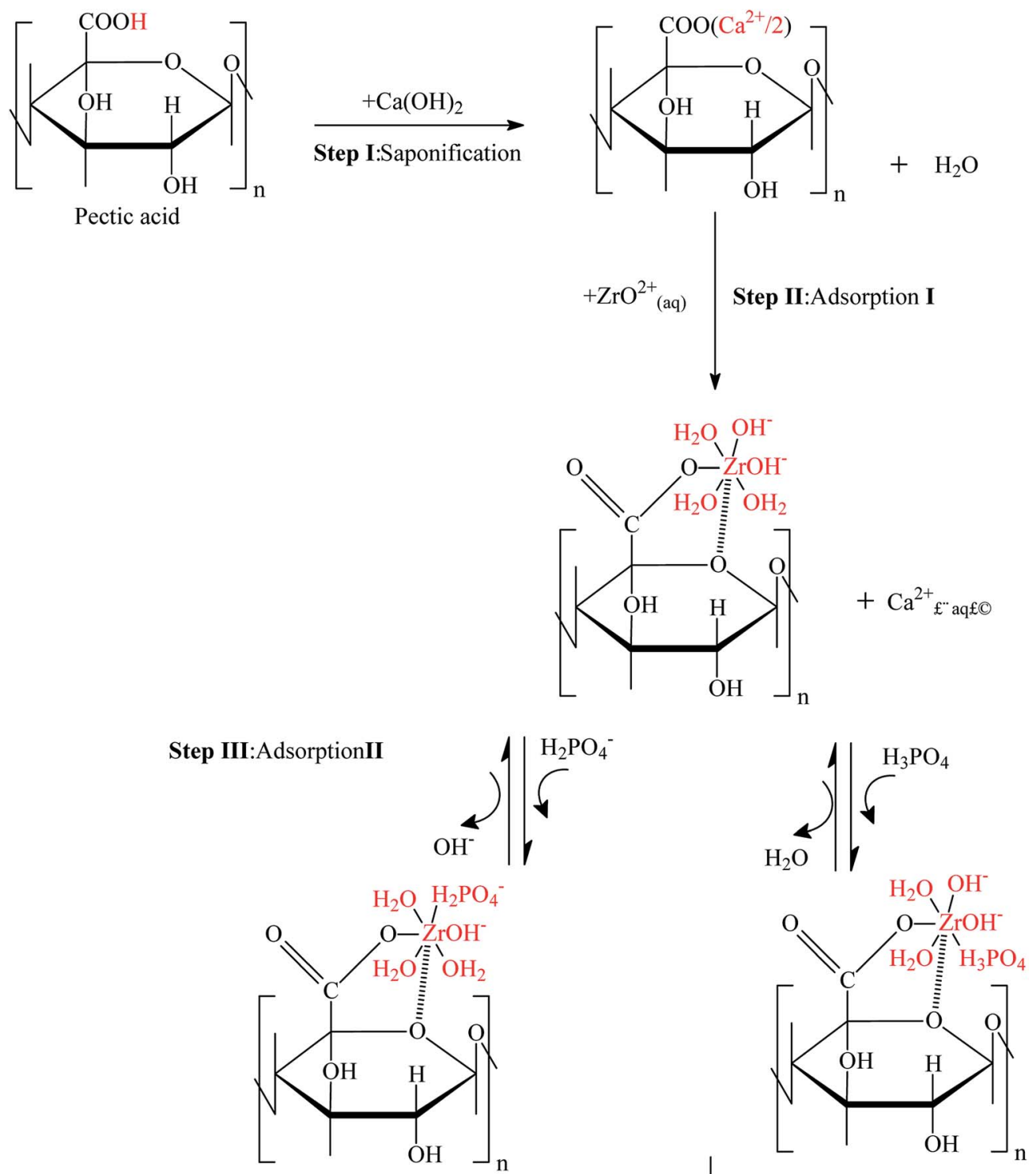

Step IV:Elution

$+\mathrm{OH}^{-}$

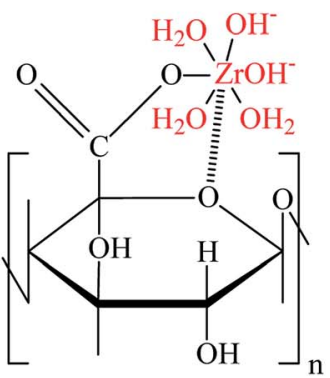

$+\mathrm{PO}_{4}{ }^{3-}{ }_{(\mathrm{aq})}$

Scheme 1 Illustration diagram of modification of pectic acid groups contained in garlic peel, and the adsorption and elution of $\mathrm{PO}_{4}{ }^{3-}$ on the $\mathrm{Zr}_{-}$ GP particles.

Based on the relative literature, we found that the acidic functional groups such as polyphenolic $-\mathrm{OH}$ and $-\mathrm{COOH}$ were probably the main role that contributed to the adsorption of metal ions onto the garlic peel particles, ${ }^{21}$ and in our experimental study it was found that $\mathrm{pH}$ of the soaking solution of crushed raw garlic peel decreased drastically which shows the 
obvious acidity. Based on the comprehensive information, we deduced the principal mechanisms of the chemical modification of garlic peel and the phosphate adsorption and desorption process on the Zr-GP particles, as shown in Scheme 1, in which chemical modification was more like a neutralization process between the biomass acid in the garlic peel and the added calcium hydroxide, and the adsorption process of $\mathrm{ZrO}^{2+}$ was a typical cation exchange, while the adsorption/desorption (elution) of phosphate was an anion exchange process. Based on the above results, the relative mechanisms of modification and adsorption/desorption were also briefly inferred in the Scheme 1.

\section{Conclusions}

The Zr-loaded garlic peel (Zr-GP) particles was investigated on its adsorption behavior for phosphate, and it was found that at pH near 1.0 the maximum adsorption capacity was attained, and higher $\mathrm{pH}$ would inhibit the adsorption. While considering the stability of the Zr-GP and efficient repeating adsorption/ elution operations, $\mathrm{pH}$ at 1.5 or a little higher level is recommended to avoid the possible dissolution of zirconium from the Zr-GP particles. Coexisting anions such as $\mathrm{Cl}^{-}$and $\mathrm{SO}_{4}{ }^{2-}$ had no obvious effect on the adsorption of phosphate, while $\mathrm{F}^{-}$greatly affected phosphate adsorption. The adsorption efficiency for phosphate from model solution is still kept at $85 \%$ after 5 cycles of adsorption-desorption. From the acid leach liquor of iron ore, the phosphate was effectively adsorbed by Zr-loaded garlic peel particles, and the eluted solution contained highly pure $\mathrm{Na}_{3} \mathrm{PO}_{4}$ and $\mathrm{NaOH}$. The Zr-loaded garlic peel particles showed great potential of application in the recovery of extracted phosphate anions from the acid leach liquor of the real iron ore, and it may be a feasible technical choice for the dephosphorization of iron ore if the total economic and technical cost is acceptable.

\section{Conflicts of interest}

There are no conflicts to declare.

\section{Acknowledgements}

The present work was financially supported by the special fundamental funds by Beijing Education Committee for the project of garlic waste reuse for toxic metals removal and recovery of valuable metals (Grant No. 04020007), and the Open funds by State Key Laboratory of Advanced Metallurgy (No. KF1405).

\section{References}

1 C. Y. Cheng, V. N. Misra, J. Clough and R. Muni, Miner. Eng., 1999, 12, 1083-1092.

2 P. Delvasto, A. Valverde, A. Ballester, J. A. Muñoz, F. González, M. L. Blázquez, J. M. Igual and C. GarcíaBalboa, Hydrometallurgy, 2008, 92, 24-129.

3 K. Ionkov, S. Gaydardzhiev, A. Corream de Araujo, D. Bastin and M. Lacoste, Miner. Eng., 2013, 47, 119-127.

4 A. P. L. Nunes, C. L. L. Pinto, G. E. S. Valadão and P. R. M. Viana, Miner. Eng., 2012, 39, 206-212.

5 P. J. Williams and T. E. Cloete, J. Biotechnol., 2010, 150, 372373.

6 H. Q. Tang, Z. C. Guo and Z. L. Zhao, J. Iron Steel Res. Int., 2010, 17, 1-6.

7 W. T. Xia, Z. D. Ren and Y. F. Gao, J. Iron Steel Res. Int., 2011, 18, 1-4.

8 K. Q. Li, W. Ni, M. Zhu, M. J. Zheng and Y. Li, J. Iron Steel Res. Int., 2011, 18, 9-13.

9 Y. S. Jin, T. Jiang, Y. B. Yang, Q. Li, G. H. Li and Y. F. Guo, J. Cent. South Univ. Technol., 2006, 6, 673-677.

10 K. C. Bal Krishna, A. Aryal and T. Jansen, J. Environ. Manage., 2016, 180, 17-23.

11 Y. H. Pan, Food Nutrition in China, 2012, 18, 22-26.

12 Z. Naheed, Z. Cheng and C. Wu, Postharvest Biol. Technol., 2017, 131, 39-45.

13 Y. Zhao, W. Li and J. Liu, Chem. Eng. J., 2017, 326, 745-755.

14 K. Huang, S. Q. Jiao and H. M. Zhu, Int. Conf. Mater. Renewable Energy Environ., 2013, 1, 604-607.

15 B. Liang, W. H. Zhao, K. Huang and H. M. Zhu, Appl. Mech. Mater., 2014, 694, 382-386.

16 C. Y. Ma, Z. Li, W. H. Zhao, Y. Xu, G. R. Cui, Y. F. Xiu and K. Huang, Appl. Mech. Mater., 2014, 694, 367-371.

17 K. Huang, J. G. Shao, H. M. Zhu and K. Inoue, J. Cent. South Univ. Technol., 2011, 181, 448-1453.

18 K. Huang and H. M. Zhu, China Pat., CN 201210019531.6, 2012.

19 K. Huang, S. Q. Jiao and H. M. Zhu, Proc. TMS. Annu. Meet., 2012, pp. 289-296.

20 B. K. Biswas, K. Inoue, K. N. Ghimire, H. Harada, K. Ohto and H. Kawakita, Bioresour. Technol., 2008, 99, 8685-8690.

21 C. Jantra, D. C. Slaughter and P. S. Liang, Postharvest Biol. Technol., 2017, 33, 98-103. 